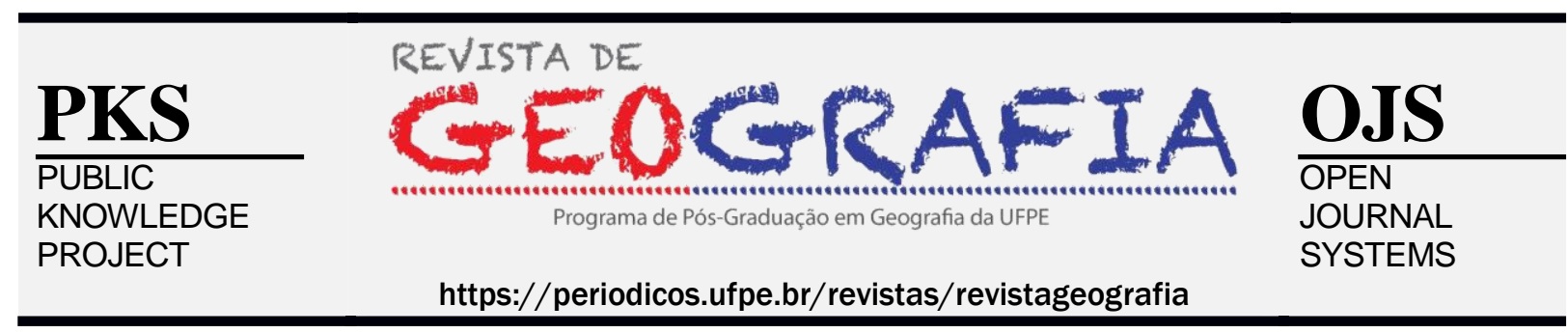

\title{
MOBILIDADE DO TRANSPORTE URBANO NA CIDADE DE CUIABÁ: DIFICULDADES DO AUMENTO DAS FROTAS DE VEÍCULOS AUTOMOTORES
}

\author{
Adriana Maria Rodrigues ${ }^{1}$, Juliana Rosa Campos de Souza ${ }^{2}$, Francisca Kaline \\ Bezerra de Souza ${ }^{3}$, Cornélio Silvano Vilarinho Neto ${ }^{4}$
}

\begin{abstract}
${ }^{1}$ Mestre em Geografia pela Universidade Federal de Matogrosso. E-mail:adrianarodrigues_tur@hotmail.com ${ }^{2}$ Mestre em Geografia pela Universidade Federal de Matogrosso. E-mail: julianarosamestrado@gmail.com ${ }^{3}$ Mestre em Geografia pela Universidade Federal de Matogrosso.E-mail: kalinebsouza@gmail.com

${ }^{4}$ Professor do Programa de Pós-graduação em Geografia pela Universidade Federal de Matogrosso. Email: csvn1943@yahoo.com
\end{abstract}

Artigo recebido em 02/02/2018 e aceito em 25/12/2019

\begin{abstract}
RESUMO
Nos últimos anos tem havido um aumento considerável de transportes no perímetro urbano e consequentemente a desordem no deslocamento desses veículos que dificultam o fluxo do trânsito nas cidades. O incentivo governamental à aquisição de automóveis e o déficit dos transportes públicos têm levado as pessoas a optarem pelo transporte motorizado individual, gerando problemas como congestionamentos, acidentes e outros conflitos de trânsito. Entretanto, a racionalização de viagens tem sido uma forma de redução da velocidade, de tempo, assim promovendo a acessibilidade a todos. O objetivo deste artigo foi em verificar como a política de incentivo da produção industrial de veículos e a grande liberação de crédito na última década influenciou o "inchaço" nas cidades, acarretando um impacto da mobilidade urbana na Cidade de Cuiabá-MT.
\end{abstract}

Palavras-chave: Mobilidade Urbana. Cuiabá. Racionalização.

\section{MOBILITY OF URBAN TRANSPORTATION IN THE CITY OF CUIABÁ: DIFFICULTIES OF THE INCREASE OF FLEETS OF AUTOMOTIVE VEHICLES}

\begin{abstract}
In the last years there has been a considerable increase in the number of vehicles in the urban perimeter, producing consequently disorders in the movement of these vehicles and hinderingthe traffic flow. in the cities. The government's incentive to purchase automobiles and the deficit in public transport have led people to opt for individual motorized transportation, causing problems such as traffic jams, accidents and other traffic conflicts. However, the rationalization of trips has been a way of reducing speed and time, thus promoting accessibility to all. The objective of this article was to verify how the policy of encouraging the industrial production of vehicles and the great liberation of credit in the last decade influenced the "swelling" in the cities, resulting in an impact of urban mobility in the city of Cuiabá-MT.
\end{abstract}

Key-words: Urban mobility. Cuiabá. Rationalization. 


\section{INTRODUÇÃO}

Nas últimas décadas devido o crescimento dos grandes centros urbanos houve a necessidade de investimentos em transportes, pois a população, principalmente, a concentrada nas periferias necessita dos meios de transportes para o seu deslocamento diário, que na maioria das vezes implicam em uma sequência de etapas com características próprias de frequência, tempo de viagem e conforto.

Os transportes no Brasil baseiam-se em várias modalidades como: trens suburbanos, bondes, metrô, trólebus e ônibus, os três últimos considerados como modalidades principais, quando operam em faixas privativas e com direitos preferenciais de passagem. Na cidade de Cuiabá somente em 1880 surgem os bondes por tração animal, em 1882 foram implantados os bondes elétricos. A partir dos anos de 1925, o ônibus urbano logo chega à cidade de Cuiabá depois os automóveis particulares como forma de independência e autonomia para as pessoas se deslocarem. (STIEL, 1984).

As regiões metropolitanas brasileiras, apesar da descentralização, ainda apresentam um quadro de grande dependência de suas periferias aos núcleos centrais, em termos de emprego e serviços. Os fluxos de viagens entre as periferias e a área central permitem identificar, ainda, ao rebatimento espacial de graves desequilíbrios socioeconômicos: populações de baixo poder aquisitivo frequentemente marginalizada mora em lugares cada vez mais distantes, pagando um preço elevado pelo transporte coletivo, em geral deficiente e moroso. (MELLO, 1981).

Sendo uma preocupação crescente, os problemas advindos da temática trânsito têm despertado/necessitado a atenção e intervenção do Estado. O crescimento da cidade sem planejamento adequado tem aumentado consideravelmente o percurso diário dos cidadãos para a prática das suas atividades diárias, como ir ao trabalho, à escola, ou na busca por lazer. Este fator, aliado a um ineficiente sistema de transporte público, expõe as pessoas a necessitarem cada vez mais de um meio de locomoção particular. Bernadinho (2007) destaca que as "aglomerações urbanas e as relações humanas vêm instaurando uma complexidade social nunca antes atingida", onde o aumento dos deslocamentos viários tem contribuído para que ocorram os acidentes de trânsito.

Atualmente, Cuiabá possui aproximadamente 585.367 mil habitantes e uma área territorial de $3.291,816 \mathrm{~km}^{2}$ conforme dados do Instituto de Geografia e Estatística - IBGE (2016). A capital do Estado de Mato Grosso tem suas origens arraigada a descoberta aurífera no início do século XVIII, onde o ouro foi à base econômica responsável pelo surgimento 
tanto da cidade como do Estado, Vilarinho, (2008) salienta que "a cidade de Cuiabá influencia tanto no desenvolvimento da Região Centro-Oeste quanto no desenvolvimento da Região Amazônica, pois, a mesma se transformou em um polo de desenvolvimento no Estado em relação às atividades econômicas, sociais, urbanas e prestação de serviços”. Nesse sentido, Souza e Salazar (2016) pontuam que Cuiabá vive uma variação populacional durante o dia, uma vez "sendo polo da oferta de serviços, emprega vários trabalhadores dos municípios adjacentes que chegam à cidade tanto pelo transporte coletivo, como em seus veículos particulares". A frota de automóveis licenciados para o município de Cuiabá segundo dados da Secretaria de Mobilidade Urbana é de 261.015 automóveis e de 105.023 motocicletas até dezembro de 2015.

Pensando sobre os incentivos fiscais e financeiros que propiciaram o aumento vultoso do consumo de veículos automotores nas grandes e pequenas cidades brasileiras, refletindo diretamente no adensamento e piora dos problemas urbanos, pensou-se em desenvolver neste artigo uma análise do crescimento da frota veicular para o município de Cuiabá na última década, e os problemas causados por este aumento. Este artigo é organizado em tópicos pra melhor compreensão, após a introdução, é disposta a parte da fundamentação teórica composta pelos sub-tópicos: Mobilidade Urbana; Políticas Públicas, e este trás uma divisão falando das Políticas públicas de desenvolvimento urbano, de mobilidade urbana, desenvolvidos a nível nacional e local especificamente de Cuiabá; em seguida inicia-se a discussão do impacto da Política Pública de facilidade das linhas de créditos na modalidade de financiamento no período de 2007 a 2013 sobre a frota de veículos em Cuiabá, este tópico é compreendido pelos sub-tópicos: Suspensão do Veto à Política Industrial; Avanços na Coordenação da Política Industrial e Crise Mundial; finalizando o artigo estão os tópicos que trazem os Resultados e discussões, em seguida as considerações finais e as referências.

\section{FUNDAMENTAÇÃO TEÓRICA}

\section{Mobilidade urbana}

Para o deslocamento a um determinado lugar existem vários fatores que influenciam na mobilidade em uma cidade e principalmente na escolha do transporte como: condição física e financeira, familiares e oferta de meios de transporte.

A mobilidade urbana constitui-se pelo conjunto de políticas de transporte e circulação; Atributo relacionado aos deslocamentos realizados por indivíduos nas suas atividades na cidade; Condição em que se realizam os deslocamentos de pessoas e cargas no espaço urbano. 
"Habilidade de movimentar-se, em decorrência de condições físicas e econômicas" (VASCONCELLOS, 2001).

A mobilidade urbana é um atributo das cidades e se refere à facilidade de deslocamento de pessoas e de bens no espaço urbano. Tais deslocamentos são feitos através de veículos, vias, e de toda a infraestrutura calçadas, que possibilitem esse ir e vir cotidiano [...] é o resultado da interação entre os deslocamentos de pessoas e bens com a cidade. (BRASIL, 2006).

Silva (1982) considera que a relação entre transporte público e periferia não pode ser isolada do conjunto de problemas urbanos que afetam as condições de vida na cidade, entendendo-se a mobilidade, particularmente aquela exercida para o trabalho, como um elo entre as condições de inserção no meio urbano (por meio da habitação) e da inserção no sistema produtivo (via condições de trabalho). Trata-se, desta forma, de debater um fenômeno existente no cotidiano, que é da classe trabalhadora urbana, relacionada com a venda efetiva de força de trabalho.

O espaço urbano é constantemente modificado, ou seja, faz parte dos conflitos e contradições que estão relacionados diretamente com a mobilidade urbana para a garantia do acesso das pessoas no perímetro urbano ou não.

\section{POLÍTICAS PÚBLICAS}

O Estado realiza intervenções na sociedade por meio do uso de políticas públicas, principalmente em áreas como a do desenvolvimento socioambiental, que muitas vezes têm objetivos conflitantes com o desenvolvimento econômico.

É importante ressaltar a definição de Saravia (2006) que afirma que política pública é de um sistema de tomada de decisão para realizar ou não ações de prevenção ou correção de problemas de ordem pública que se destinam a modificar ou manter estável a realidade social, por meio da determinação de objetivos e estratégias, considerando os recursos a serem alocados para viabilizar sua realização.

As políticas públicas são desenvolvidas a partir do desenvolvimento por órgãos direta ou indiretamente vinculados a administração, ou seja, regido pelo artigo $37^{\circ}$ da Constituição Federal Brasileira que devem atender aos princípios da legalidade, impessoalidade, moralidade, publicidade e eficiência.

\section{Políticas públicas de desenvolvimento urbano}


A concentração da população brasileira nas áreas urbanas tem ocorrido com bastante intensidade nas últimas décadas, e com isto, tem-se como consequência o aumento de diversos problemas nas cidades, como violência, falta de planejamento urbano, falta de infraestrutura, entre outros. Em geral, destaca-se que as cidades brasileiras tiveram planejamento precário em sua concepção e as políticas públicas são ineficientes ou inexistentes. Esses problemas acumulados até a década de 1970 fortaleceu o movimento social urbano que teve início no mesmo período e acumulou forças nas duas décadas seguintes na luta pela democratização do País e pela reforma urbana. Nesse contexto, a fim de criar uma instância federal voltada para as políticas urbanas, foi criado o Ministério das Cidades, que teve sua estrutura baseada nos três principais problemas sociais que afetam as populações urbanas, e que estão relacionados ao território, elencados por Maricato (2005) sendo eles: a moradia, o saneamento ambiental que agrega água, esgoto, drenagem e coleta e destinação de resíduos sólidos e as questões reunidas sob o tema do transporte da população urbana - mobilidade e trânsito.

Deste modo, o governo federal, juntamente com a participação social, desenvolveu a Política Nacional de Desenvolvimento Urbano (PNDU) - Caderno MCidades 1 (BRASIL, 2004). O processo de formulação do PNDU, contou com a participação social, e conferências nacionais, sendo a primeira Conferência Nacional de Cidades em 2003, e a segunda em 2005. As conferências foram precedidas de várias políticas sociais, conferências municipais e estaduais onde puderam tratar e debater propostas e teses, bem como eleger representantes para a conferência nacional.

Para uma cidade ser desenvolvida, ou as atividades urbanas acontecerem de forma satisfatória existem vários fatores que devem ser pensados e correlacionados, ou seja, deve haver uma visão mais ampla dos problemas a ser resolvido, cada qual em sua esfera, sendo municipal, estadual ou federal. A criação do Ministério das Cidades e a formulação da PNDU foram primordiais para inclusão da questão urbana na agenda política brasileira.

\section{Políticas públicas de mobilidade urbana}

Nos últimos anos, a questão da mobilidade urbana refletiu um marco legal inovador no Estatuto da cidade Lei $\mathrm{n}^{-}$10.257, de 17 de julho de 2001, que instituiu o tratamento da temática no corpo da lei, estatuindo a obrigatoriedade do desenvolvimento dos Planos Diretores de Transportes Público para municípios brasileiros com população acima de 500 mil habitantes com foco no serviço motorizado de transporte público. Em 2005 a Resolução nº 34 
do Conselho de Cidades alterou o nome para Plano de Transporte e Mobilidade PDTM e junto a isso previu um conteúdo mínimo do PDTM, que entre outros aspectos, pontuou a observância das diversas modalidades de transporte, respeitando as especificidades locais, a priorização do coletivo sobre o individual, os modos não motorizados e os pedestres. Ainda nesse sentido, o Ministério das Cidades publicou, em 2007, um guia para orientações aos órgãos gestores municipais na elaboração dos PDTMs, calcado nos princípios da mobilidade urbana sustentável, nos conceitos da Resolução no 34 do Conselho das Cidades e no então Projeto de Lei (PL) no 166 do Senado Federal, que trata da Política Nacional da Mobilidade Urbana PNMU. Após 10 anos de aprovação do Estatuto da Cidade, o tema pouco se desenvolveu nos municípios, apesar dos esforços empreendidos pela União para promover o desenvolvimento dos PDTMs.

A luz dessas discussões foi aprovada em 3 de janeiro de 2012 a Lei 12.587 que instituiu as diretrizes da Política Nacional de Mobilidade Urbana, objetivando a integração entre os diferentes modos de transportes e a melhoria da acessibilidade e mobilidade das pessoas e cargas no território do município. Conforme positivado em seu Art. 2o a PNMU tem por objetivo:

"[...] contribuir para o acesso universal à cidade, o fomento e a concretização das condições que contribuam para a efetivação dos princípios, objetivos e diretrizes da política de desenvolvimento urbano, por meio do planejamento e da gestão democrática do Sistema Nacional de Mobilidade Urbana”.

Além de diretrizes, princípios e objetivos, observa-se na PNMU uma lista de temas que devem ser tratados em prol de uma mobilidade sustentável nos municípios, entre os quais pode-se destacar a necessidade de tratar os serviços de Transporte Público Coletivo (TPC), a integração modal, os polos geradores de tráfego e os instrumentos de financiamento do sistema de transporte público (STP), bem como do sistema de mobilidade. Além dos aspectos já citados, a PNMU determina que elementos como o uso do espaço da circulação viária sejam regulamentados, estabelecendo posturas a serem seguidas no caso do transporte de cargas, bem como da política de estacionamentos. Ou seja, indica alguns instrumentos de gerenciamento de demanda que podem ser utilizados para dar um uso mais racional para o espaço urbano.

O prazo estipulado no Art. $24 \S 3^{\circ}$ para integração do Plano de Mobilidade Urbana ao plano diretor municipal, existente ou que estivesse em elaboração, era no prazo máximo de 3 (três) anos da vigência Lei 12.587 aprovada em 3 de janeiro de 2012, no entanto, o prazo foi 
prorrogado pela Medida Provisória Número 748 publicada em 11 de outubro de 2016 estendendo o prazo para 7 (sete) anos a partir da data de vigência da Lei. Findando-se o prazo, aqueles que não elaborassem o Plano de Mobilidade Urbana, conforme Art. $24 \S 5^{\circ}$ ficariam impedidos de receber "[...] recursos orçamentários federais destinados à mobilidade urbana até que atendam à exigência estabelecida nesta Lei”.

\section{Plano de mobilidade urbana no município de Cuiabá}

Embora a Lei 12.587 de 3 de janeiro de 2012 ter instituído o prazo máximo de 3 (três) anos para a elaboração do Plano de Mobilidade Urbana, a partir da data de vigência da lei, logo, encerrando-se no ano de 2016, (fato alterado pela Medida Provisória 748 de 11 de outubro de 2016), em Cuiabá os estudos para efetivação do mesmo só começaram a partir de janeiro de 2015, quando da troca de gestor da secretaria competente para gerir a temática de Mobilidade Urbana no município, inclusive ocorrendo nesse mesmo período, a troca do nome da Secretaria que denominava-se "Secretaria Municipal de Transporte Urbano" e passou a denominação de "Secretaria Municipal de Mobilidade Urbana", o fato dessa troca de denominação, substituindo os termos "Transporte Urbano" por "Mobilidade Urbana" pode ser indicativo de uma mudança de visão sobre o objeto de atuação das políticas públicas voltadas para o tema em Cuiabá.

Analisando a gestão atual da Mobilidade Urbana em Cuiabá, é possível constatar que há uma preocupação em se atender aos objetivos e diretrizes firmadas no Plano Nacional de Mobilidade Urbana, no tocante ao transporte público coletivo, foram instituídas mudanças nas rotas para otimização do atendimento a população, criação de faixas exclusivas para ônibus visando a diminuição do tempo de viagem, renovação parcial da frota de ônibus da cidade a fim de dar mais conforto aos usuários, quanto a priorização do transporte não motorizado, foi implantada na cidade $10 \mathrm{~km}$ de Ciclo-faixa, localizadas no entorno da Arena Pantanal, seguindo para a Avenida Miguel Sutil até o Parque Mãe Bonifácia, outra região abrangida foi a compreendida na Avenida Arquimedes Pereira Lima e Avenida das Torres na região que abrange os bairros Santa Cruz I e II, Jardim Imperial, Recanto dos Pássaros e adjacências, outro ponto foi na região da grande Morada do Ouro que recebeu aproximadamente $3 \mathrm{~km}$ de ciclo-faixa, sendo que o município contava apenas com $6 \mathrm{~km}$ de ciclo-faixa até 2015, foram implantadas mais 440 faixas de segurança para travessia de pedestres, há um trabalho conjunto entre as Secretarias Municipais de Mobilidade Urbana, Ordem Pública de Obras e Serviços Urbanos, visando a intensificação da fiscalização no uso e implantação/adequação de 
calçadas e passeios públicos objetivando dar melhores condições de mobilidade às Pessoas com Deficiência e restrição de mobilidade.

Foram feitas alterações nos fluxos de vias e revitalização e implantação de sinalização viária nas regiões centrais e outras centralidades dentro da cidade, intensificação na fiscalização da legislação de trânsito e controle da velocidade nas principais vias, visando à redução do número de acidentes e consequentemente diminuição dos números de feridos graves. Quanto à operação e o disciplinamento do transporte de carga na infraestrutura viária, está em vigor desde 2011 a Lei 5.463 que regulamenta as áreas e horários de restrição de circulação de veículos pesados, e houve intensificação na fiscalização com a implantação do Centro Integrado de Controle de Mobilidade Urbana, tais medidas têm surtido efeitos ainda sutis no que tange a continuidade do tráfego de veículos pesados, uma vez que é possível verificar em alguns pontos a existências de caminhões e carretas em locais não permitidos.

Conforme o Secretário da Pasta, tais melhorias foram possíveis a partir do direcionamento correto do valor arrecadado das multas e do trabalho conjunto com o Chefe do governo executivo municipal.

\section{O IMPACTO DA POLÍticA PÚBLICA DE FACILIDADE DAS LINHAS DE CRÉDITOS NA MODALIDADE DE FINANCIAMENTO NO PERÍODO DE 2007 A 2013 SOBRE A FROTA DE VEÍCULOS EM CUIABÁ}

\section{Suspensão do veto à política industrial}

Nesse período a frota de veículos na cidade de Cuiabá teve aumento significativo, portanto, faz-se necessário analisar a situação política e econômica em que o Brasil se encontrava no período. Em janeiro de 2003, tomou posse na Presidência do País, um novo presidente que manteve a princípio a política macroeconômica de seu antecessor, onde acontecia uma combinação de variáveis: combinação do regime de metas de inflação com o câmbio flutuante e a política de superávit fiscal primário, visando à continuidade do controle inflacionário.

Com a política monetária freando recorrentemente o crescimento da demanda doméstica, o principal estímulo para a expansão da produção industrial somente poderia vir do comércio exterior, aquecido pela crescente demanda das economias asiáticas, em especial da China. Com as exportações em trajetória rapidamente crescente, as restrições externas diminuíram significativamente no governo da época. Se de um lado deu continuidade à política macroeconômica anterior, de outro lado o governo logo acabou com o veto à Política 
Industrial e iniciou a formulação da Política Industrial, Tecnológica e de Comércio Exterior (PITCE), elaborada ao longo de vários meses, contando com a contribuição de notórios especialistas em política industrial, tecnológica e de comércio exterior.

Esta combinação contraditória criou um grave paradoxo, na medida em que, estando fortemente limitado em mover os instrumentos clássicos do câmbio, dos juros e do gasto público, não teria como soltar as amarras para a política industrial. Bem recebida por muitos, a implementação da PITCE teve, no entanto, que enfrentar muitas dificuldades, entre elas a herança herdada dos anos 1990, quando foram extintas ou esvaziadas muitas das instâncias de coordenação e de planejamento que desempenharam papel importante ao longo do processo de industrialização: conselhos interministeriais, órgãos de planejamento entre outros., além das instâncias que existiam no interior das empresas públicas de infraestrutura que foram privatizadas.

Na lista dos sobreviventes: as esvaziadas agências de desenvolvimento regional, um Banco Nacional de Desenvolvimento Econômico e Social - BNDES desfigurado, o Banco do Brasil - BB e a Caixa Econômica Federal - CEF com atuações acanhadas, o Serviço Brasileiro de Apoio às Micro e Pequenas Empresas - SEBRAE com atuação isolada, alguns outros arranjos institucionais, além de um conjunto desarticulado de instrumentos, criados em geral para minimizar distorções geradas pela política econômica. De acordo com os documentos oficiais, a PITCE consubstanciada em um conjunto de 57 medidas distribuídas em 11 programas de política propunha-se articular três planos distintos: 1) Linhas de ação horizontais inovação e desenvolvimento tecnológico; inserção externa; modernização industrial; ambiente institucional/aumento da capacidade produtiva; 2) Opções estratégicas semicondutores, software, bens de capital e fármacos; 3) Atividades portadoras de futuro biotecnologia, nanotecnologia, biomassa/energias renováveis. Eram dois os macroprogramas mobilizadores: I) Indústria forte visando fortalecer e expandir a base industrial brasileira; II) Inova Brasil visando aumentar a capacidade inovadora das empresas. Um plano de ação que explicitava como objetivos o aumento da eficiência da estrutura produtiva, o aumento da capacidade de inovação das empresas brasileiras e a expansão das exportações. Essa seria a base para uma maior inserção do País no comércio internacional, estimulando os setores onde o Brasil teria maior capacidade ou necessidade de desenvolver vantagens competitivas e abrindo caminhos para inserção nos setores mais dinâmicos dos fluxos de troca internacionais.

\section{Avanços na coordenação da política industrial e crise mundial}


O segundo mandato do Presidente inicia dando continuidade à PITCE, conforme Bresser-Pereira (2009) entre janeiro de 2007 e maio de 2008, inúmeras iniciativas continuaram sendo Política industrial do governo, texto para discussão. Ao mesmo tempo, foi-se trabalhando na formulação de uma nova fase da PITCE (Fase II) que representasse um avanço em termos de abrangência e potência, bem como se articulasse mais firmemente com outros programas de governo, visando aprofundar a trajetória de recuperação da capacidade do Estado de formular e gerenciar políticas.

Em 12 de maio de 2008, um novo programa de promoção à indústria brasileira é lançado pelo governo federal, com maiores pretensões no sentido de sua abrangência, profundidade, articulações, controles e metas, ampliando o número de setores e os instrumentos de incentivo em relação à PITCE. Entre os avanços, está a preocupação em definir objetivos e estabelecer metas, fortalecer a coordenação entre diferentes instituições do governo e o diálogo com o setor privado, dentro de uma visão sistêmica voltada à construção da competitividade de longo prazo dos mais diversos setores da economia brasileira. Batizada de Política de Desenvolvimento Produtivo - PDP e apoiando-se em diversos tipos de medidas (tributária/fiscal, financiamento, poder de compra por parte do governo, aprimoramento jurídico, regulação e apoio técnico, a nova política tem como objetivo a sustentação de um longo ciclo de desenvolvimento produtivo, apoiado no investimento, na inovação, na competitividade das empresas e na ampliação das exportações). Entre outros instrumentos, o novo programa propõe a desoneração de diversos setores produtivos correspondente a uma renúncia fiscal de R \$ 21,4 bilhões entre 2008 e 2011 Suzigan e Furtado (2010) apontaram em 2007, em trabalho apresentado no II Congresso Brasileiro de Inovação na Indústria, que há um número excessivo de órgãos com precária capacidade de mobilizar recursos, administrando instrumentos dispersos e desarticulados e com poucos quadros técnicos com formação adequada. Neste caso, o desafio seria avançar na integração da PITCE com outros importantes programas em curso: Plano de Aceleração do Crescimento - PAC; Plano de Ação Ciência, Tecnologia e Inovação - PACTI; Plano de Desenvolvimento da Educação - PDE; Programa Mais Saúde (PAC-Saúde); Plano Nacional de Qualificação - PNQ; Programa de Mobilização da Indústria Nacional de Petróleo e Gás Natural - PROMINP; Programa Educação para a Nova Indústria.

Observamos que nesse período diversos fatores influenciaram substancialmente a elevação do número de veículos no Brasil, e consequentemente em Cuiabá. Entre eles: a eliminação do IOF nas operações de crédito do BNDES, a redução à zero do IR incidente em 
despesas com prestação no exterior de serviços de logística de exportação, a redução a zero do IR incidente na promoção comercial no exterior de serviços prestados por empresas brasileiras, a depreciação acelerada para o setor automotivo, a depreciação acelerada para o setor de bens de capital, a dedução em dobro da base de cálculo do IRPJ e da CCLL das despesas c/capacitação de pessoal próprio das empresas de software, a suspensão da cobrança de IPI, PIS e COFINS sobre peças e materiais destinados à construção de navios novos p/estaleiros nacionais, ampliação do prazo de recolhimento do IPI pelo setor automotivo, entre outros.

Observando o gráfico 1 e a tabela 1 abaixo, podemos ver como esse processo na economia foi um fator determinante para o inchaço da malha viária de Cuiabá.

Gráfico 1: Evolução da Frota da cidade de Cuiabá

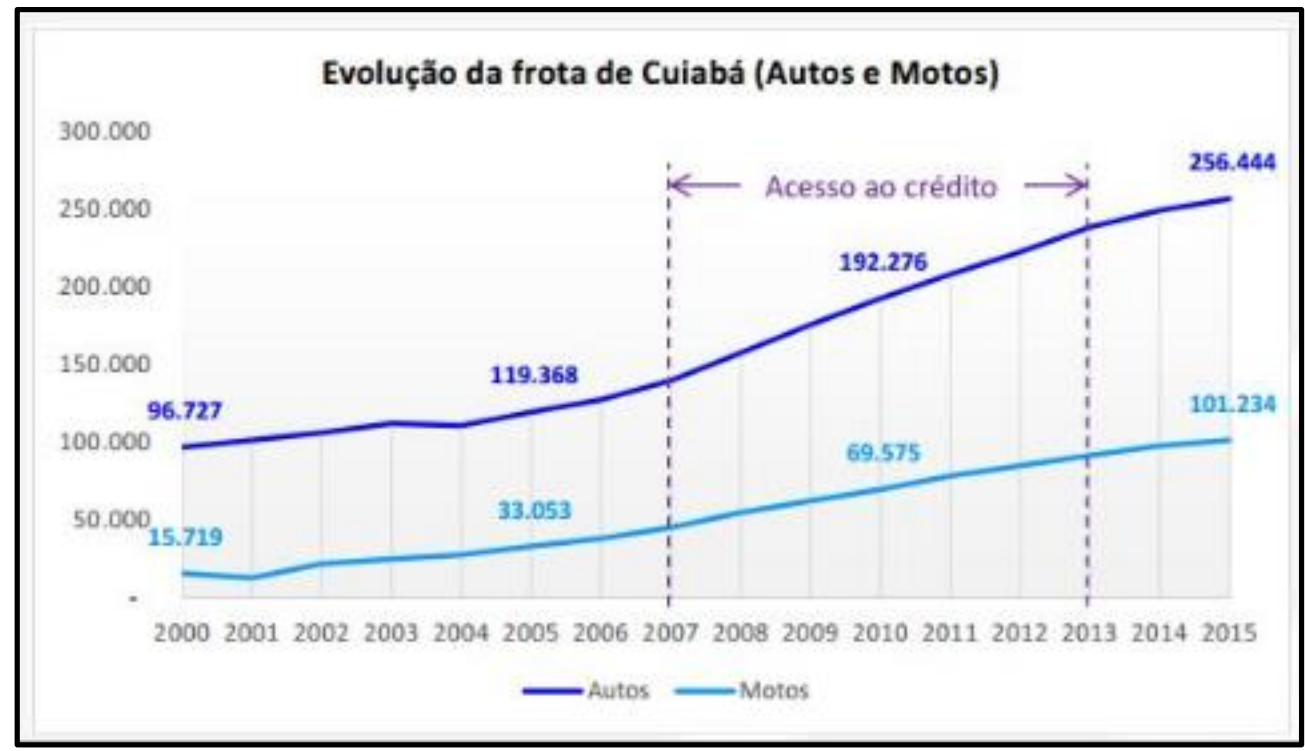

Fonte: Secretaria de Mobilidade Urbana 2016

Tabela 1: Frota total dos anos de 2000 a 2015 da cidade de Cuiabá

\begin{tabular}{|l|c|c|r|}
\hline & 2000 & 2007 & $\mathbf{2 0 1 5}$ \\
\hline Frota total * & 125.178 & 202.101 & 580.489 \\
Frota Autos (A) & 96.727 & 139.694 & 256.44 \\
Frota Motos (M) & 15.719 & 45.054 & 101.23 \\
Frota Autos + Motos & 112.446 & 184.748 & 357.67 \\
Crescimento frota (A)+(M): 2000 à 2007 & & $64 \%$ & \\
Crescimento frota (A)+(M): 2000 à 2015 & & & $218 \%$ \\
Populaçăo (P) ** & 483.346 & 526.830 & 580.48 \\
Crescimento populacional (\%) *ref: 2000 & & $9 \%$ & $20 \%$ \\
Indice de Motorizaçäo (hab/veic) & 4,3 & 2,9 & 1,6 \\
\hline
\end{tabular}

Fonte: Secretaria de Mobilidade Urbana 2016 


\section{RESULTADO E DISCUSSÃO}

A concentração urbana, a distribuição irracional de horários de atividades gerando deslocamentos pendulares simultâneos, a precariedade do transporte coletivo e o sistema viário insuficiente são um convite ao desenvolvimento de soluções de "software urbano", procurando racionalizar os deslocamentos e as atividades dentro da infraestrutura já existente.

A maioria dos deslocamentos inevitavelmente deve ocorrer em determinado momento nas condições permanentes, entretanto pouca gente conjectura se há ou não alternativa.

A partir da informação obtida para enfrentar um deslocamento com o trânsito muito lento, deve-se, quando possível:

- Alterar o horário, o percurso, o modo de transporte e/ou o destino da viagem.

- Não executar a viagem.

- Enfrentar com consciência a dificuldade e ir em frente.

De toda forma é melhor se ter várias opções do que apenas uma. Uma questão da qual muito se fala, mas pouco se faz é a implantação concreta de medidas que diminuam o tamanho e o número de deslocamentos, como, por exemplo, uma legislação que beneficie assentamentos de áreas-dormitório próximas a postos de trabalho. Mesmo que em escala relativamente pequena, o impacto no trânsito seria significativo.

O escalonamento dos horários de trabalho ou das diferentes atividades até certo ponto já existe, porém sua ampliação costuma atrapalhar a vida de quem tem mais de uma atividade (geralmente escola e trabalho).

Há poucos dados e estudos consistentes a esse respeito. Infelizmente o debate tem sido muito baseado em "achismos". Note-se, entretanto, que as facilidades da informática, do geoprocessamento, dos bancos de dados e das simulações eletrônicas poderiam iluminar muito essa discussão. Melhores soluções apareceriam.

O transporte de cargas com caminhões grandes, médios e pequenos ajuda a complicar a situação. Não faltaram tentativas nos últimos anos em usar horas ociosas de pouco movimento para se fazer o transporte e a operação de carga e descarga. O transportador gosta da ideia, a população que enfrenta o trânsito aplaude, entretanto os responsáveis pelos pontos de recebimento não concordam em ter em seu estabelecimento equipes de pessoal e segurança para receber a carga em horários não-comerciais. $\mathrm{O}$ acordo nunca foi possível.

É de se notar que propostas alternativas de uma distribuição mais inteligente de viagens ou deslocamentos são formas de melhorar o trânsito sem grandes investimentos, 
porém é necessária muita vontade política para convencer as pessoas, físicas ou jurídicas, inclusive políticos, a mudarem de comportamento.

Muitos preferem a liberdade de perder tempo e dinheiro no congestionamento a alterar hábitos. Não se podem discutir medidas de racionalização de deslocamentos sem que se considere o rodízio municipal. Se não é uma solução profunda, inegavelmente hoje diminui o número de quilômetros de congestionamento no centro expandido da cidade.

Se pudéssemos ter uma foto aérea de todo o sistema viário da cidade na hora de pico da tarde, por exemplo, não teríamos certamente toda a frota de veículos circulando ao mesmo tempo, pois isso não é mais possível há décadas. Se cada munícipe motorizado, usando seu direito constitucional de ir e vir tivesse a ideia de sair na mesma hora com seu veículo, isso seria fisicamente impossível. A cidade já se "afoga" em congestionamentos com $25 \%$ da frota circulando ao mesmo tempo. Portanto, a solução do rodízio guarda dentro de si uma dinâmica que anula com o tempo o benefício pretendido, não somente pela aquisição de um segundo veículo (geralmente mais poluidor), como também a reserva de carros viáveis no rodízio vai sendo mobilizada.

Outra limitação do rodízio, que é uma regulamentação que pretende ser sistêmica, é a fiscalização manual, portanto parcial e precária. Mesmo assim, cada dia perto de três mil condutores são multados por desrespeitar o rodízio. A prefeitura tem um desafio ainda não suficientemente abordado: como administrar a escassez crescente de espaço para circular. A solução tem de ser tecnicamente viável e socialmente o mais justa possível. Hoje quem não tem veículo próprio e é usuário cativo de ônibus é penalizado pelo congestionamento provocado pelo carro particular. É injusto!

Quando existe uma escassez de um bem público, deve ser administrada a cobrança pelo uso. É o caminho de maior justiça e viabilidade. A cidade adotou esse caminho, quando criou, há mais de 20 anos, a Zona Azul. Faltava espaço para todos estacionarem livremente junto ao meio fio e decidiu-se cobrar pelo uso. É bom lembrar que depois de grande celeuma foi o próprio comércio, que antes reclamava que passou a solicitar a ampliação do sistema. Isso porque eram os próprios comerciantes que deixavam seus carros estacionados, impedindo o uso de vagas para seus clientes. Foi fácil mostrar que cada vaga passou a ser usada em média por quatro ou cinco carros cada dia. Houve, portanto, aumento de capacidade. Hoje São Paulo tem 29 mil vagas de Zona Azul. Em qualquer sistema viário saturado a retirada efetiva de $20 \%$ dos veículos que circulam principalmente nos horários críticos representa um efeito de fluidificação do trânsito. Resta discutir como retirá-los. É oportuno lembrar que, ao 
contrário de países como o Japão, aqui, mesmo sem provar que se tem onde guardar o veículo, o cidadão pode comprá-lo sem qualquer impedimento. A experiência internacional (como a do México) não recomenda o rodízio "dia par com par" como eficaz o suficiente. Inevitavelmente a cidade deverá debater a solução do trânsito tarifado ou o pedágio urbano. $\mathrm{O}$ agravamento da dificuldade de circular e o crescimento do número de quilômetros de congestionamento, fazendo aumentar ainda mais a escassez de espaço viário, leva a se considerar o deslocamento em automóvel particular, em vias saturadas e nas horas de pico, um verdadeiro privilégio.

O espaço é insuficiente para atender a toda à demanda. A tarifação das vias saturadas nos horários mais críticos por meio de controle eletrônico que possibilita a identificação do veículo em movimento deve garantir a retirada de circulação nas vias tarifadas de $20 \%$ da frota, o que possibilita fluidificar o trânsito. O sistema não tarifa áreas, e sim vias, o que resulta de fato em melhor distribuição de deslocamento do veículo particular no uso do sistema viário público.

O pedágio urbano é uma tese debatida há muito tempo. Um dos motivos de sua nãoutilização era a falta de tecnologia para identificar o veículo em movimento, dificuldade hoje superada no Brasil. A tarifação do trânsito urbano já é aplicada em algumas partes, e a comunidade técnica mundial transformou-a em assunto de grande atualidade. $\mathrm{O}$ pagamento direto pelo exercício de privilégio do uso de um bem cuja oferta é escassa permite reinjetar os recursos arrecadados na ampliação do sistema de transporte coletivo de qualidade, o que, por sua vez, facilitará ainda mais a retirada de carros particulares de circulação. É importante alocar custos de modo mais equitativo, associando-o ao uso, em vez de socializá-lo por via tributária. Uma das formas, talvez a melhor, de se associar o pedágio urbano à implantação de projetos definidos como, por exemplo, o metrô, o rodoanel e o monitoramento eletrônico do trânsito é transferir a tarefa para a iniciativa privada.

O poder concedente não investe, apenas controla, regulamenta e garante a aplicação dos recursos para as finalidades previstas e visíveis ao público usuário. Tecnicamente o problema já está resolvido; entretanto o ponto crucial encontra-se na decisão política da cobrança do pedágio. Muitas vezes o político quer buscar saídas a partir de ações simpáticas e indolores. Não raramente fixa-se no poder das grandes obras, vive a frustração da falta de recursos para realizá-las e ignora o certo potencial administrativo, técnico e político das medidas operacionais e de racionalizar o uso do espaço e da infraestrutura existentes. A 
resistência em se arbitrar uma tese mais ousada e moderna resultará no agravamento e na degradação da qualidade de vida urbana.

\section{CONSIDERAÇÕES FINAIS}

O propósito deste trabalho foi apresentar a fragilidade na nossa política pública brasileira quando se fala em racionalização de meios de transporte diante do gigante poderio do capitalismo que se sobrepôs no Brasil, especialmente, no artigo em tela, na indústria automobilística nos anos de 2003 a 2007. Sendo assim, o foco do nosso estudo foi à cidade de Cuiabá onde tivemos acesso aos dados infográficos e a entrevista com o Secretário Municipal de Mobilidade Urbana, que demonstraram esse salto vertiginoso de acesso a veículos de uso não coletivo de forma desordenada.

Infelizmente sabe-se que não é possível pensar no meio urbano sem pensar em trânsito e no deslocamento das pessoas em seu cotidiano. Em muitos países, os problemas causados pelo trânsito são enquadrados tanto na perspectiva do meio ambiente quanto da saúde pública, imensuráveis para o impacto na qualidade de vida das pessoas. O Brasil é um País que apresenta essa desigual e iniquidade, não apenas na renda, mas também nas oportunidades de acesso aos serviços públicos essenciais. Nos transportes urbanos isso não poderia ser diferente. Diante disso conclui-se que o transporte público coletivo, por sua vez, é tratado com menosprezo, para pessoas com baixo poder aquisitivo, não merecendo ser contemplado como atividade estratégica por parte da União, estados ou municípios. As cidades têm sido moldadas para atender unicamente ao automóvel, arrastando o transporte público sem prioridade para uma crise de perda de atratividade.

Considera-se que sejam adotadas medidas permanentes para melhorar as condições de conforto e acessibilidade aos usuários do transporte coletivo, sugere-se que seja estudada a possibilidade de implantação de rotas que abranjam os bairros mais longínquos dos centros, bem como uma maior oferta em horários de rush, pode-se também implantar abrigos nos pontos de parada, oferecendo mais condições de conforto. Quanto à acessibilidade no transporte coletivo, faz-se necessária a implantação de novos ônibus equipados com elevadores para o transporte de Pessoas com Deficiências - PCD que fazem uso de cadeira de rodas ou que tenham a mobilidade reduzida. Quanto à estruturação das vias, calçadas, ruas nota-se que ao se deslocar na cidade de Cuiabá há um descaso em seu planejamento e execução desde sua formação que foi advinda da exploração do ouro, e isso se transformou 
em uma cultura perante os governantes e a sociedade. Portanto tal política impõe uma das piores iniquidades - a da acessibilidade.

\section{REFERÊNCIAS}

BRASIL. Caderno 1 MCIDADES. Política nacional de desenvolvimento urbano. Ministério das Cidades: Brasília, 2004.

BRASIL, Caderno 2. Construindo a cidade acessível. Secretaria nacional de transporte e da mobilidade urbana. Ministério das cidades. 1 ed. Brasília, 2006.

BRASIL. Lei n. 12.587, de 03 de janeiro de 2012. Política nacional de mobilidade urbana. Disponível em: <http://www.planalto.gov.br/ccivil_03/_ato2011-2014/2012/lei/112587.htm>. Acesso em: 10 out. 2016.

BERNADINHO, A. R. Espacialização dos acidentes de trânsito em Uberlândia (Mg): técnicas de geoprocessamento como instrumento de análise - 2000 a 2004. $268 \mathrm{f}$. Tese (Doutorado em Geografia) - Faculdade de Filosofia, Letras e Ciências Humanas da Universidade de São Paulo, São Paulo, 2007.

BRESSER-PEREIRA, L. C. A crise financeira de 2008. Revista de Economia Política, v. 29, n. 1, p. 133, 2009.

IBGE, População. 2010. Disponível em: <http://www.ibge.gov.br/população>. Acesso em: 15 nov. 2016.

MARICATO, E. 2005. O ministério das cidades e a política nacional de desenvolvimento urbano. Disponível em:<http://repositorio.ipea.gov.br/handle/11058/4508 >Acesso em: 08 nov. 2016.

MELLO, J. C. Planejamento dos transportes urbanos. Rio de Janeiro: Editora Campo LTDA. 1981. 
SARAVIA, E. Introdução à teoria da política pública. In: SARAVIA, E.; FERRAREZI, E. Políticas públicas. Brasília: ENAP, 2006.

SECRETARIA DE MOBILIDADE URBANA. PREFEITURA DE CUIABA. Evolução da frota em Cuiabá (Autos e Motos). 2016. Disponível em: <http://dadostrafego.cuiaba.promultonline.com.br/Relatorio/NaoInfratores> Acesso em: 11 nov. 2016.

SILVA, A. A. - Transporte e periferiall. In: Revista de estudos regionais e urbanos espaço e debates. Ano II, n. 07. São Paulo: Cortez, 1982.

SOUZA, F. K. B \& SALAZAR, M. M. Z. O uso de ferramenta de geoprocessamento na análise dos acidentes de trânsito em Cuiabá. In: SEMANA DA GEOGRAFIA NA UFMT, 2016, 19., Cuiabá. Anais... Cuiabá: UFMT, 2016. p. 8.

SUZIGAN, W.; FURTADO, J. Instituições e políticas industriais e tecnológicas: reflexões a partir da experiência brasileira. Estudos Econômicos, São Paulo, v. 40, n. 1, p. 7-41, 2010.

STIEL, W. C. História do transporte urbano no Brasil: bondes e trólebus: "summa tranviariae brasiliensis”. EBTU. Edição Convênio. 1984.

VASCONCELLOS, E. A. Transporte urbano, espaço e equidade: reflexões e propostas. $2^{a}$ ed, São Paulo: Annablume, 2001.

VILARINHO, C. S. N. Cuiabá, uma metrópole regional. In: ROMANCINE, S. R. (Org). Novas territorialidades urbanas em Cuiabá. Cuiabá: EdUFMT/FAPEMAT, 2008. 